\begin{tabular}{|c|c|c|}
\hline $\begin{array}{l}\text { PKS } \\
\begin{array}{l}\text { PUBLIC } \\
\text { KNOWLDGE } \\
\text { PROJECT }\end{array}\end{array}$ & $\begin{array}{c}\text { REVISTA DE GEOGRAFIA } \\
\text { (RECIFE) } \\
\text { http://www.revista.ufpe.br/revistageografia }\end{array}$ & 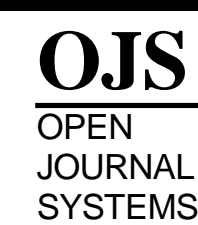 \\
\hline
\end{tabular}

\title{
ANÁLISE DOS EVENTOS DE CHUVA EXTREMA E SEUS IMPACTOS EM FORTALEZA-CE, DE 2004 A JANEIRO DE 2015
}

\author{
Iohanna Bezerra Rrodrigues ${ }^{1}$; Júlia Monteiro Holanda ${ }^{2}$; Dayane Siqueira Gonçalves ${ }^{3}$; Marta \\ Celina Linhares Sales ${ }^{4}$ \\ ${ }^{1}$ Mestranda no Programa de Pós-graduação em Geografia da Universidade Federal do Ceará. Email: \\ iohannabr@hotmail.com \\ ${ }^{2}$ Mestranda no Programa de Pós-graduação em Geografia da Universidade Federal do Ceará. Email: \\ juliamonteiro.h@gmail.com \\ ${ }^{3}$ Mestranda no Programa de Pós-graduação em Geografia da Universidade Federal do Ceará. Email: \\ dayanedesiqueira@yahoo.com.br \\ 4 Professora Doutora do Departamento de Geografia da Universidade Federal do Ceará. Email: \\ mclsales@uol.com.br
}

Artigo recebido em 20/07/2015 e aceito em 15/08/2017

\begin{abstract}
RESUMO
O presente trabalho objetiva fazer uma análise acerca dos eventos de chuva extrema que ocorrem em Fortaleza. Entender o ritmo climático na capital citada se torna imperativo posto o elevado índice de áreas de risco, onde a população se encontra, muitas vezes, despreparada para lidar com eventos climáticos atípicos. Nesse sentido, fez-se uma análise dos anos de 2004 a janeiro de 2015 com o intuito de identificar a quantidade de eventos climáticos extremos, considerando as chuvas acima de $60 \mathrm{~mm} / 24 \mathrm{~h}$ como já causadoras de impactos negativos sobre o ambiente urbano (ZANELLA, 2006; ZANELLA, SALES e ABREU, 2009; GONÇALVES, 2011). Foram utilizados dados da estação meteorológica do PICI que é mantida pela FUNCEME, imagens de satélite do CPTEC/INPE, Cartas sinóticas da Marinha do Brasil e reportagens e imagens veiculadas pela mídia local. Apesar de ter sido feita uma análise ao longo desses dez anos, foi enfocado neste trabalho o último evento extremo da série histórica, devido sua proporção a nível de perdas materiais e sua baixa intensidade pluviométrica. Espera-se que os estudos envolvendo essa temática sirvam como subsídio à gestão municipal quanto à prevenção de perdas materiais e até mesmo humanas em caso de eventos extremos.
\end{abstract}

Palavras-chave: Eventos extremos; Climatologia Dinâmica; Fortaleza.

\section{ANALYSIS OF THE EXTREME EVENTS AND IMPACTS IN FORTALEZA - CE, OF THE YEARS 2004 TO JANUARY 2015}

\begin{abstract}
This paper aims to make an analysis about the heavy rainfall events that occur in Fortaleza. Understanding the climate rhythm in the capital mentioned is imperative because of the high risk areas index, where the population is often unprepared to deal with atypical weather events. In this sense, there was an analysis of the years 2004 to January 2015 in order to identify the amount of extreme weather events, considering the rainfall above 60 $\mathrm{mm} / 24 \mathrm{~h}$ as causing negative impacts on the urban environment (ZANELLA, 2006 ; ZANELLA, SALES and ABREU, 2009; GONÇALVES, 2011). Was used PICI weather station data maintained by FUNCEME, satellite CPTEC / INPE images, synoptic charts of the Navy of Brazil and reports and images broadcast by local media. Although it was an analysis over ten years, was focused in this work the last extreme event of the series, because their proportion in terms of material losses and low rainfall intensity. It is hoped that studies involving this theme serve as subsidy to the municipal administration regarding the prevention materials and even human losses in case of extreme events.
\end{abstract}

Keywords: Extreme Event; Dynamic Climatology; Fortaleza City.

Rodrigues et al., 2017 ISSN 0104-5490




\section{INTRODUÇÃO}

O estudo dos eventos pluviométricos intensos é importante para o conhecimento da realidade climática de um local e também, para compreender e avaliar a consequência dos impactos que eles geram em diferentes setores da sociedade. Grande parte dos eventos extremos de chuvas quando alcançam áreas ocupadas, sobretudo os aglomerados urbanos, impactam negativamente o sistema socioeconômico dessas localidades.

As cidades são uma realidade que se impõe cada vez mais no mundo moderno, o crescimento da população urbana é um fato indiscutível, assim, a cidade se torna um grande centro polarizador das atividades produtivas, culturais, sociais, etc. onde a grande maioria das pessoas almeja viver. A cidade é, segundo Carlos (1997) "o espaço produzido para atender as necessidades do capital e da reprodução humana", Monteiro (2011) também fala que a cidade é obra de uma natureza retrabalhada para os propósitos humanos, ou seja, o homem que vive nesse ambiente procura fazer modificações na natureza, necessárias, para atender as suas necessidades.

Para Mendonça (2010, p.10) "a degradação do ambiente e, consequentemente a queda da qualidade de vida se acentuam onde o homem se aglomera: nos centros urbanoindustriais". Sendo assim, as alterações e modificações na natureza são mais intensas na cidade e é por isso que o impacto dos fenômenos naturais são maiores nessas áreas, junto a isso, se soma o grande contingente populacional das cidades que favorece o aumento da vulnerabilidade.

No Brasil os fenômenos naturais adversos estão, geralmente, ligados à dinâmica climática, eles se expressam sobre a forma de chuvas intensas, geadas, secas, tornados e tempestades (MONTEIRO, 2011; GONÇALVES, 2011; TOMINAGA; SANTORO e AMARAL, 2009).

No perímetro urbano são as chuvas intensas ou aguaceiros as principais causadoras de perturbação, desordem e perdas, tanto de vida como materiais, e isso implica diretamente na qualidade de vida das pessoas. Monteiro (2011) fala que quase todas as áreas metropolitanas brasileiras sofrem com problemas de inundação sendo palco de várias calamidades.

Com a maior intensidade dos impactos que os eventos extremos vêm causando na sociedade urbana, cresce a notoriedade do tema no ambiente acadêmico, com a publicação de um número considerável de pesquisas na temática. Este trabalho também compartilha das 
mesmas ideias, onde, aborda a temática dos impactos meteóricos de chuvas concentrados na cidade de Fortaleza.

A capital cearense é uma metrópole que concentra grande contingente populacional e que cresceu de maneira desordenada, como a grande maioria das cidades brasileiras. Em dias de chuva intensa (por vezes nem tão intensas) a cidade vivencia uma situação caótica onde grande parcela da população sofre para se locomover devido aos congestionamentos que se formam, principalmente pelos alagamentos, causando uma serie de transtornos urbanos. A população que sofre relevantes perdas materiais e até humanas, habita locais próximos às zonas de risco, localizadas essencialmente nas áreas periféricas e/ou de elevadas altitudes, que são propensas a deslizamentos ou privadas de sistemas eficientes de escoamento das águas pluviais, devido à intensa impermeabilização do solo.

Percebendo a relevância dos eventos pluviométricos de grande intensidade para dinâmica urbana de uma cidade, o presente trabalho pretende fazer uma análise dos eventos pluviométricos extremos ocorridos entre 2004 e janeiro de 2015, dentro da perspectiva do Sistema Clima Urbano (S.C.U) de Monteiro (1976 e 2011) no campo hidrometeórico, que é aquele que discute a questão dos eventos pluviométricos extremos, que via de regra se apresenta como um evento perturbador da ordem. Para selecionar os eventos de chuva extrema dentro dessa serie temporal, tomamos como parâmetro os estudos de Zanella (2006), Zanella, Sales e Abreu (2009) e Gonçalves (2011) que definem eventos de chuva extrema a partir de $60 \mathrm{~mm} / 24 \mathrm{~h}$ (ou na somatória de três dias seguidos o mesmo valor), segundo eles, esses eventos já causam efeitos negativos no ambiente urbano.

Diante do exposto, este trabalho tem como objetivo analisar dos eventos extremos de chuvas ocorridos entre o ano de 2004 e Janeiro de 2015 e seus impactos na cidade de Fortaleza, servindo de subsídios relevantes para análises de acordo com temática abordada, fornecendo informações que viabilizem políticas públicas voltadas ao planejamento urbano.

\section{METODOLOGIA}

A cidade de Fortaleza, capital do Estado do Ceará, está localizada no norte do Nordeste do Brasil, nas coordenadas $3^{\circ} 43^{\prime} 02^{\prime \prime} \mathrm{S}$ e $38^{\circ} 32^{\prime} 35^{\prime \prime} \mathrm{W}$. Fortaleza possui uma área de $314,930 \mathrm{Km}^{2}$ e é considerada a quinta mais populosa do Brasil segundo dados populacionais do IBGE, 2014. Ao Norte a cidade é banhada pelo Oceano Atlântico; ao Sul faz fronteira com os Municípios de Maracanaú, Pacatuba, Itaitinga, Eusébio; ao Leste com os 
Municípios de Eusébio, Aquiraz e com o Oceano Atlântico; e a Oeste com os Municípios de Caucaia, Maracanaú, como pode ser observado no mapa a seguir.

\section{Mapa 01 - Região Metropolitana de Fortaleza}

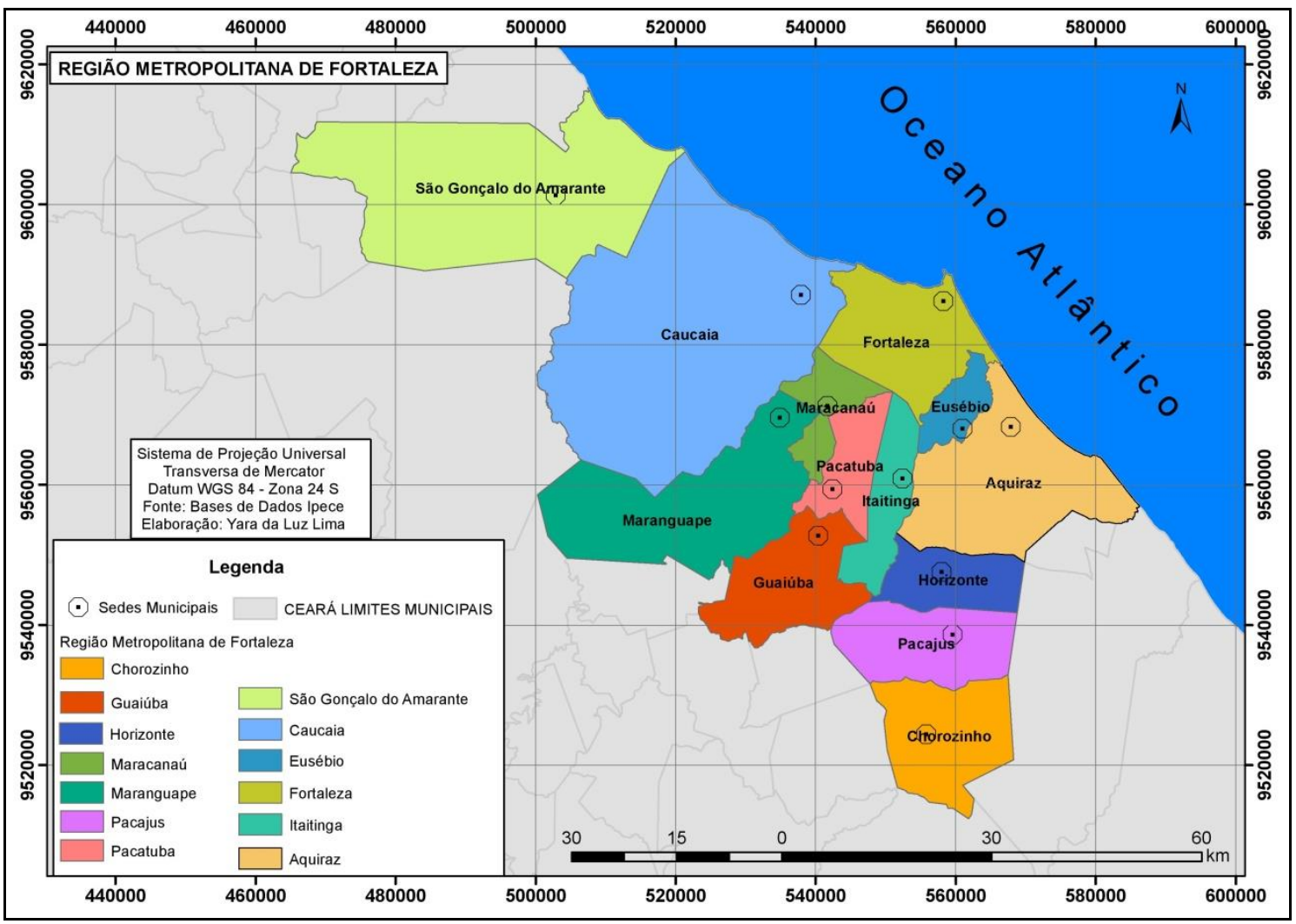

Fonte: Luz, 2013.

Fortaleza possui um quadro ambiental bem diverso, seja pelas variadas características físico-ambientais, seja pelas complexas relações sociais realizadas na mesma. As inter-relações ambientais estabelecidas resultam em um uso e ocupação diferenciados no território.

A maior parte da cidade se encontra sobre o relevo de tabuleiro pré-litorâneo que são áreas relativamente estáveis, com pouca diferença altimétrica, denominado de Glacis de deposição ${ }^{1}$. Ao norte se encontra a Planície Litorânea composta por variadas paisagens naturais como dunas, faixa praial, planícies flúvio-marinhas, entre outros, que conferem a esse ambiente uma alta vulnerabilidade frente às intervenções humanas. Quanto à drenagem,

\footnotetext{
1 São amplas faixas de leques colúvio-aluviais coalescentes, que demostram que o nível do mar era mais baixo que o atual, constituindo-se como depósitos correlativos, relacionados a erosão diferencial que ocorreu no semi-
} árido. 
Fortaleza possui riachos, lagoas, e rios sendo essas áreas altamente vulneráveis a ocupação e uso indevido. O Rio Ceará não passa por dentro da cidade, porém tem sua foz na Barra do Ceará e seu maior afluente, o Rio Maranguapinho, corta o setor leste de Fortaleza. O Rio Cocó é o mais importante rio da cidade situado na parte central e onde foi criado o Parque do Cocó, a maior área verde da cidade. A oeste o Rio Coaçu faz a divisa de Fortaleza com Eusébio e o Rio Pacoti faz a divisa da cidade com Aquiraz. Essas áreas de elevada fragilidade ambiental necessitam de maiores estudos para evitar não somente a degradação desses ambientes como também a preservação da vida e da saúde das pessoas que ali residem.

O trabalho tem como referencial metodológico o Sistema Clima Urbano (S.C.U.) proposto por Monteiro (1976 e 2011), utilizando o subsistema hidrometeórico agrupa "todas aquelas formas meteóricas, que assumindo, eventualmente manifestações de intensidade são capazes de causar impacto na vida da cidade, perturbando-a ou desorganizando-lhe a circulação e os serviços" (MONTEIRO, 2011, p.24).

Para atingir o objetivo proposto pelo autor supracitado, a pesquisa seguiu algumas etapas. A priori foi feito um levantamento bibliográfico, documental e cartográfico sobre o tema e a área de estudo. Posteriormente, para identificar os eventos de chuva iguais ou superiores a $60 \mathrm{~mm} / 24 \mathrm{~h}$ ocorridos na cidade de Fortaleza no período de 2004 e janeiro de 2015, utilizou-se de dados do posto pluviométrico do Campus do Pici da Universidade Federal do Ceará, que foi fornecido pela Fundação Cearense de Meteorológica e Recursos Hídricos (FUNCEME).

O último procedimento foi a caracterização sinótica do dia de chuva acima de $60 \mathrm{~mm} / 24 \mathrm{~h}$ ocorrida em Janeiro de 2015 , nessa etapa, identificamos os sistemas atmosféricos atuantes com base em cartas sinóticas fornecidas pelo CPTEC/INPE e nas imagens de satélite fornecidas pelos mesmos. Escolhemos este ano, pois, ele foi o evento mais recente dentro da série histórica analisada e devido aos impactos que o mesmo provocou na cidade.

Já para a análise dos impactos desse mesmo evento, na cidade de Fortaleza, utilizouse de informações fornecidas pelos jornais locais e de dados disponibilizados pela Defesa Civil do Estado do Ceará.

\section{FORTALEZA: METRÓPOLE DESIGUAL E VULNERÁ VEL}

A cada momento, tempo e espaço se alteram. Santos (2008) sinaliza que o espaço é o conjunto indissociável dos sistemas de objetos e dos sistemas de ações, onde, a cada época, 
novos objetos e ações somam-se as já existentes, modificando a totalidade espacial. Dantas (2008) menciona que a reprodução espacial se dá a partir das necessidades de reprodução da vida humana. Sendo assim, conforme a sociedade e suas demandas se alteram, o espaço se transforma, resultando em novas formas de organização espacial.

Nesse contexto, a dinâmica urbana fortalezense é intensa, passando por processos ininterruptos de transformações intensificadas pelo processo de urbanização, acarretando alterações substanciais em sua fisionomia e estrutura urbana, mudanças estas que têm afetado sensivelmente a qualidade de vida da metrópole ${ }^{2}$ fortalezense.

A população de Fortaleza vem crescendo significativamente ao longo dos últimos 50 $\operatorname{anos}^{3}$, porém com a ausência de infraestrutura urbana adequada e de políticas apropriadas de emprego e renda para dar suporte ao crescimento considerável da população resultando no espraiamento da malha urbana fortalezense para municípios adjacentes e no surgimento de aglomerados subnormais, ocupação de áreas de risco ${ }^{4}$ e de lotes de terras clandestinos, fazendo de Fortaleza e da de sua Região Metropolitana, locus de uma população vulnerável socialmente estabelecida em áreas vulneráveis ambientalmente (PEQUENO, 2009).

Enquanto Fortaleza é dotada de áreas de extrema pobreza, possui tantas outras com o padrão de vida similar ao de países desenvolvidos. Carlos (2007) aponta que esta relação dialética do espaço urbano é proveniente das contradições que estão postas no mundo moderno e que se evidenciam na metrópole, fazendo das cidades representações espaciais das diferenças. A segregação do espaço urbano se faz presente, tornando os segmentos da sociedade mais empobrecidos incapazes de ter acesso a uma parcela da "cidade formal" 5 , restando-lhes apenas áreas impróprias para seu espaço de vida (ACCIOLLY, 2009).

Costa (2009) afirma que o espaço urbano segregado se constitui fundamental para reprodução das relações sociais desiguais, intensificando a reprodução do capital imobiliário. $\mathrm{O}$ acesso às condições urbanas de vida ocorre de forma heterogênea, fazendo com que os segmentos sociais de maior poder aquisitivo ocupem ambientes com melhor infraestrutura e serviços, enquanto os grupos sociais de menor renda tendem a localizar-se nas chamadas

\footnotetext{
${ }^{2}$ Segundo o Instituto Brasileiro de Geografia Estatística - IBGE, através do estudo Regiões de Influência das Cidades - REGIC 2007, a cidade de Fortaleza se classifica como Metrópole na hierarquia na rede urbana brasileira.

${ }^{3}$ Dados, do CENSO 2010, apontam que a população da cidade é de 2.452 .185 de habitantes, enquanto em 1950 detinha em média 514.813 habitantes.

${ }^{4}$ Áreas de risco são classificadas como espaços que concentram populações vulneráveis socialmente e segredadas ambientalmente onde apresenta condições insalubres e inseguras. (DESCHAMPS, 2008)

5 Freitas (2004) demonstra que expressão "cidade formal” refere-se aos bairros que resultaram da iniciativa do estado em transformar a natureza para ser ocupada por usos urbanos.

Rodrigues et al., 2017 
áreas de risco, ou seja, áreas de maior exposição à situação insalubres e inseguras. (ZANELLA, et al. 2009)

Apesar de sua dinâmica urbana, Fortaleza se caracteriza como uma das cidades com os maiores contrastes socioambientais do Brasil, sua lógica da urbanização desigual "explica a incidência dos assentamentos informais em áreas ambientalmente frágeis de difícil ocupação sejam elas dunas ou baixios próximos aos rios urbanos" (FREITAS, 2004, p.8). Desta forma, Fortaleza apresenta espaços que coadunam elevados índices de vulnerabilidade social com áreas de planícies sujeitas a inundações periódicas, campos de dunas passíveis de deslizamentos e soterramentos, caracterizando alta vulnerabilidade socioambiental ${ }^{6}$ (ZANELLA, et al. 2013).

\section{EVENTOS CLIMÁTICOS EXTREMOS}

Os eventos climáticos extremos são fenômenos naturais que se intensificam provocando prejuízos econômicos e sociais. Segundo o Inventário de dados sobre eventos climáticos extremos (FIOCRUZ, 2011, p. 5) "Os eventos climáticos extremos mais frequentes no Brasil, segundo os dados da defesa civil nacional, são em ordem de importância: seca e estiagem, inundações, deslizamento e ventos fortes".

Dentre esses, as precipitações intensas são as que têm efeitos mais importantes nas sociedades, pois, as cheias súbitas associadas a chuvas fortes e breves podem ser um dos eventos extremos mais destrutivos, principalmente, nas regiões tropicais (MARENGO, 2009).

Esses fenômenos naturais, como a chuva, são normais e ocorrem com alta frequência, dentro de uma série histórica, já os eventos de chuva extrema, segundo Monteiro (2011, p.53) são "variações extremas e formas violentas do ritmo, afastamentos ou desvios dos padrões habituais, disritmias", porém, é preciso esclarecer que, esses eventos, mesmo sendo desvios dos padrões habituais, fazem parte do ritmo climático.

É nas cidades ou perímetros urbanos que essas chuvas intensas/concentradas vão causar mais danos, pois, é nessas áreas que a ação humana vai atuar mais fortemente modificando as características naturais, por exemplo impermeabilizando o solo e retirando as árvores, isso vai prejudicar a infiltração e absorção dessa água, provocando, consequentemente os alagamentos e inundações.

\footnotetext{
${ }^{6}$ Deschamps (2004) classifica vulnerabilidade socioambiental por áreas que detém em conjunto os riscos ambientais e as situações de vulnerabilidade social.

\begin{tabular}{lll}
\hline Rodrigues et al., 2017 & ISSN 0104-5490
\end{tabular}
}


Quando esses eventos climáticos extremos se tornam perigosos para a população eles são chamados de riscos climáticos. O risco climático seria a variabilidade climática associada à vulnerabilidade humana perante fenômenos atmosféricos adversos (AMS, 2000; WMO, 1992 apud MACHADO 2013).

Quando esses mesmos eventos atingem uma proporção que excede a capacidade da sociedade conviver com o impacto, sendo necessária ajuda externa, ele se torna um desastre natural. Ao analisar a vulnerabilidade socioambiental de Curitiba, Deschamps (2008, p. 207) reafirma o consenso existente entre os pesquisadores sobre o quão ocupada e urbanizada é uma área e a relação entre essa ocupação e a susceptibilidade aos desastres naturais. Para que seja caracterizado como desastre tem que haver uma relação com magnitude do evento, a repercussão no espaço, na economia, na sociedade. (GONÇALVES, 2011; TOMINAGA; SANTORO e AMARAL, 2009).

É importante compreender a diferença entre fenômeno natural, evento climático extremo, ricos climático, vulnerabilidade e desastre natural. Sabendo que cada um dos termos citados têm sua conceituação e suas implicações nos estudos climatológicos, vamos discutir, no presente trabalho, os eventos climáticos extremos, enfatizando as chuvas intensas/extremas, que no caso em questão, são definidas por precipitações iguais ou superiores a $60 \mathrm{~mm} / 24 \mathrm{~h}$.

\section{RESULTADOS E DISCUSSÃO}

Dentro da análise feita, caracterizando eventos de chuva extrema/intensa aqueles iguais ou superiores a $60 \mathrm{~mm} / 24 \mathrm{~h}$, identificamos que houve 34 eventos dessa natureza em Fortaleza distribuídos ao longo do período estudado. Desses, 17 foram de 60 a $80 \mathrm{~mm}, 9$ de 80 a $100 \mathrm{~mm}$ e 8 acima de $100 \mathrm{~mm}$ de chuva. Fica claro que os eventos acima de $100 \mathrm{~mm} / 24 \mathrm{~h}$ ocorrem com menor frequência, devido, principalmente, serem desvios extremos da media (Tabela 01). 
Tabela 01: Eventos de chuva extrema em Fortaleza - classificação (mm).

\begin{tabular}{|cc|}
\hline Classe $(\mathrm{mm})$ & Total de eventos de chuva extrema em $24 \mathrm{~h}$ \\
\hline $\mathbf{6 0 - 8 0}$ & 17 \\
\hline $\mathbf{8 0 - 1 0 0}$ & 09 \\
\hline$>100$ & 08 \\
\hline
\end{tabular}

Fonte: FUNCEME, 2015 (adaptado).

O comportamento anual desses eventos de chuva extrema varia muito ao longo dos anos, contudo, há uma ocorrência deles em praticamente todos os anos. Dentro do período em questão houve dois anos com picos de máxima ocorrência desses eventos, 2004 e 2011; e dois anos que não houve nenhuma ocorrência, 2013 e 2014. Já 2015, até o momento - Janeiro, só houve um. (Gráfico 01).

Gráfico 01: quantidade de eventos de chuva extrema por ano.

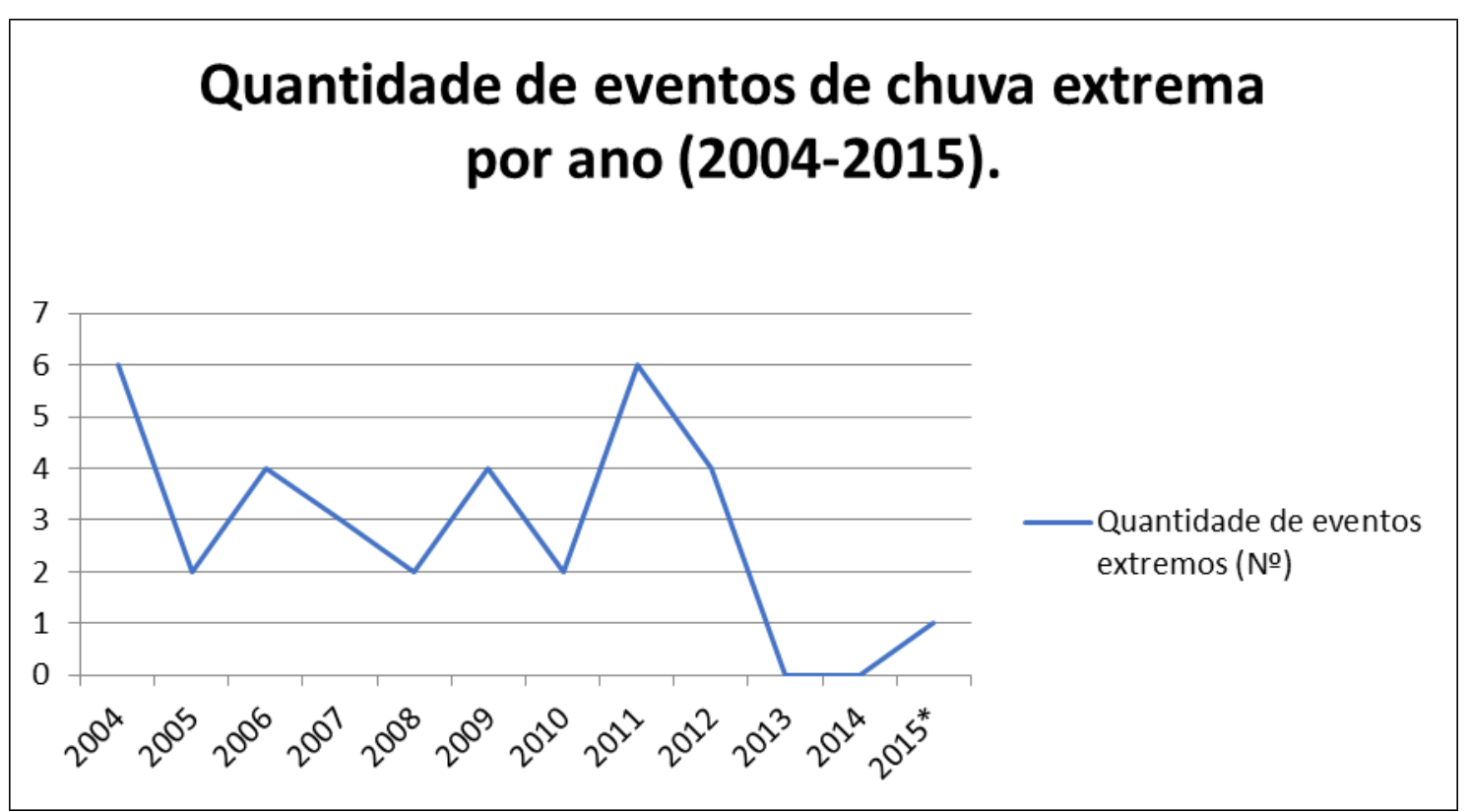

Fonte: FUNCEME, 2015 (adaptado).

Os anos analisados foram classificados segundo os parâmetros sugeridos por Sant'Anna Neto (1990) que estabelece o uso do coeficiente de variação como critério na escolha dos anos-padrão. Para ele ano chuvoso é aquele ano com pluviosidade elevada, com índices superiores a $25 \%$ da média normal; o ano tendente a chuvoso é aquele próxima à 
média normal, com desvio entre $+12,5 \%$ a $25 \%$; o ano habitual é aquele ano com pluviosidade próximo da normal climatológica, onde os desvios tem variação de $-12,5 \%$ a $+12,5 \%$; o ano tendente a seco é o ano um pouco abaixo da média normal, com desvio entre $25 \%$ a $-12,5 \%$; e o ano seco é aquele ano com pluviosidade reduzida, com índices inferiores a $-25 \%$ da média normal.

Segundo esses critérios, dos anos analisados dois foram chuvosos (2009, 2011), um foi tendente a chuvoso (2004), dois foram habituais (2006, 2008), dois foram tendente a seco $(2007,2012)$ e quatro foram secos $(2005,2010,2013,2014)$. Os anos de 2009 e 2011 foram muito acima da média (desvios acima de 40\%), isso, se deve as condições sinóticas favoráveis a chuva na região, nesses dois anos a Zona de Convergência Intertropical (ZCIT) se manteve na sua posição mais ao sul garantindo umidade para a região, segundo Ferreira e Mello (2005) a ZCIT “é o fator mais importante na determinação de quão abundante ou deficiente serão as chuvas no setor norte do Nordeste do Brasil". Além disso, os Vórtices Ciclônicos de Altos Níveis (VCAN) no ano de 2011 e as Ondas de Leste ou Distúrbios Ondulatórios de Leste (OL/DOL) em 2009 incrementaram esse cenário propiciando umidade para além da quadra chuvosa.

Já de 2012 a 2014 tem se caracterizado como anos abaixo da média pluviométrica, essa sequência de anos secos tem prejudicado a recarga de água dos reservatórios do Estado de maneira geral, esses anos são anos onde o fenômeno El Niño tem atuado, esse fenômeno se caracteriza pelo aquecimento das águas superficiais do Pacifico alterando a circulação da Célula de Walker que provoca inibição da formação de nuvens e da descida da ZCIT prejudicando as chuvas na região (FERREIRA e MELLO, 2005).

O comportamento mês a mês desses eventos, também revela algumas características interessantes (Gráfico 02). A primeira delas é muito obvia, esses eventos de chuva extrema, ocorrem no primeiro semestre do ano, isso se deve a característica do clima local que concentra as chuvas nesse período. Zanella, Sales e Abreu (2009), fizeram a análise de eventos de chuva extrema em Fortaleza, num período de 33 anos e encontraram apenas um evento dessa natureza fora desse período, ocorrido em dezembro com intensidade de 60$80 \mathrm{~mm} / 24 \mathrm{~h}$, porém, é necessário deixar claro que dezembro já e pré-estação chuvosa. 
Gráfico 02: distribuição de eventos de chuva extrema por mês.

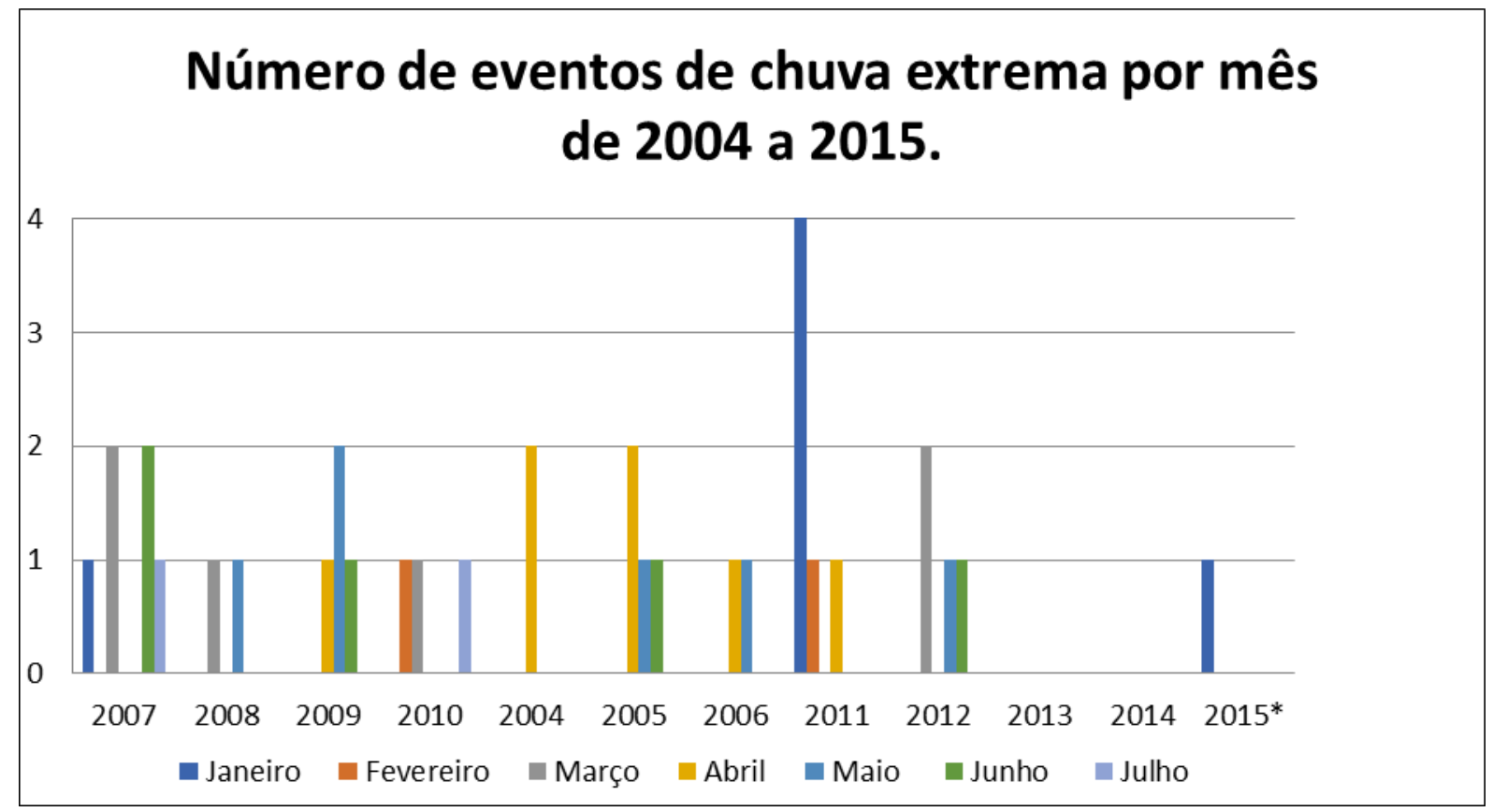

Fonte: FUNCEME, 2015 (adaptado).

Outro fato que chama atenção no Gráfico 02 é o pico de janeiro de 2011. O mês de janeiro se apresenta como um dos meses onde mais ocorrem eventos de chuva extrema em Fortaleza isso se deve a atuação dos VCAN, como já dito anteriormente, esses sistemas são característicos da pré-estação chuvosa, o mês onde eles mais ocorrem é o mês de janeiro e a maior frequência deles e no verão (FERREIRA, RAMÍREZ e GAN, 2009).

Ainda com relação à distribuição desses eventos nos meses, fizemos um Gráfico (03), com a soma desses eventos, para identificar o mês em que mais eles ocorrem. $\mathrm{O}$ trimestre que mais ocorrem esses eventos é o trimestre março-abril-maio, que é também o trimestre mais chuvoso do ano. O mês de abril é o mês que maior ocorrência desses eventos, isso se explica ao fato de a ZCIT se encontrar em sua posição mais ao sul neste mês. 
Gráfico 03: Quantidade de eventos de chuva extrema por mês.

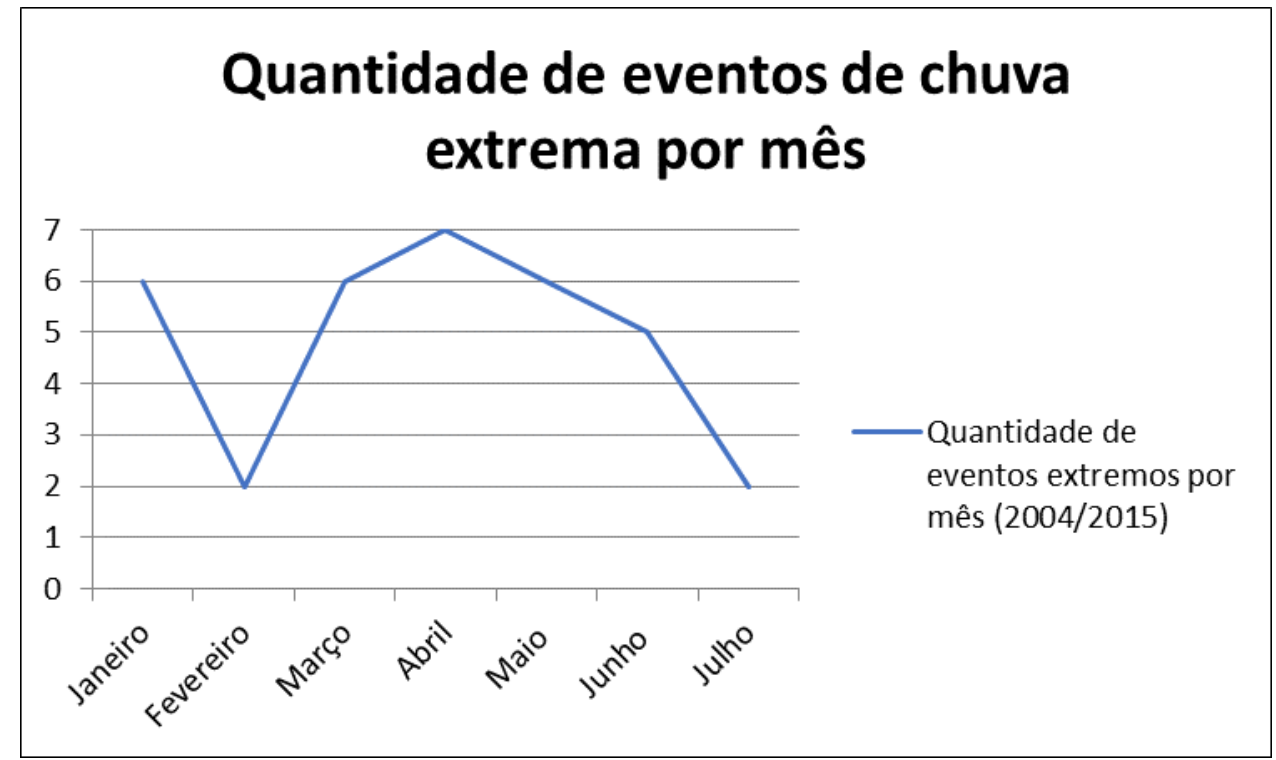

Fonte: FUNCEME, 2015 (adaptado).

Para uma melhor compreensão dos eventos de chuva extrema/intensa e de seus impactos sobre a cidade de Fortaleza decidimos fazer um estudo mais aprofundado do evento ocorrido em janeiro de 2015, buscando entender a situação sinótica do dia, com o objetivo de identificar qual sistema atuava no momento do evento e fizemos um levantamento dos impactos desse evento na cidade de Fortaleza.

\section{- Análise do evento de chuva extrema em Janeiro de 2015 e seus impactos em Fortaleza.}

Nesse trabalho decidimos analisar com mais afinco o evento de chuva extrema de janeiro de 2015, pois, ele ocorreu recentemente causando uma serie de transtornos para a população da cidade principalmente para aqueles que vivem em zonas de risco. Houve problemas de alagamentos em vários pontos da cidade, prejudicando o trânsito e o deslocamento das pessoas, além disso, houve deslizamento de um morro ocupado e várias casas foram invadidas pela água.

No dia 03 de janeiro de 2015 choveu em Fortaleza 66,6 mm de chuva segundo dados do posto do Pici (FUNCEME), um evento de chuva intensa, ocasionado principalmente por um VCAN que segundo dados do segundo o Boletim Técnico do INPE (Instituto Nacional de Pesquisas Espaciais) estava sobre o Nordeste e porção norte da Região Sudeste com centro sobre o Atlântico Tropical em torno de $03^{\circ} \mathrm{S} / 38^{\circ} \mathrm{W}$, ainda segundo o Boletim Técnico, a 
circulação associada a este sistema favorece a formação de nebulosidade desde o norte de GO até o norte do Nordeste, acelerando o escoamento e aumentando a instabilidade.

Segundo a Acessória de Informação da FUNCEME, além do VCAN outro sistema atuava no dia do evento foram as OL/DOL, apesar das ondas de leste serem sistemas mais frequentes nos meses de junho e julho, elas foram responsáveis pela intensificação dessa chuva, principalmente, na RMF.

\section{IMAGEM 01: A- CARTA SINÓTICA B- IMAGEM DO SATÉLITE METSAT.}

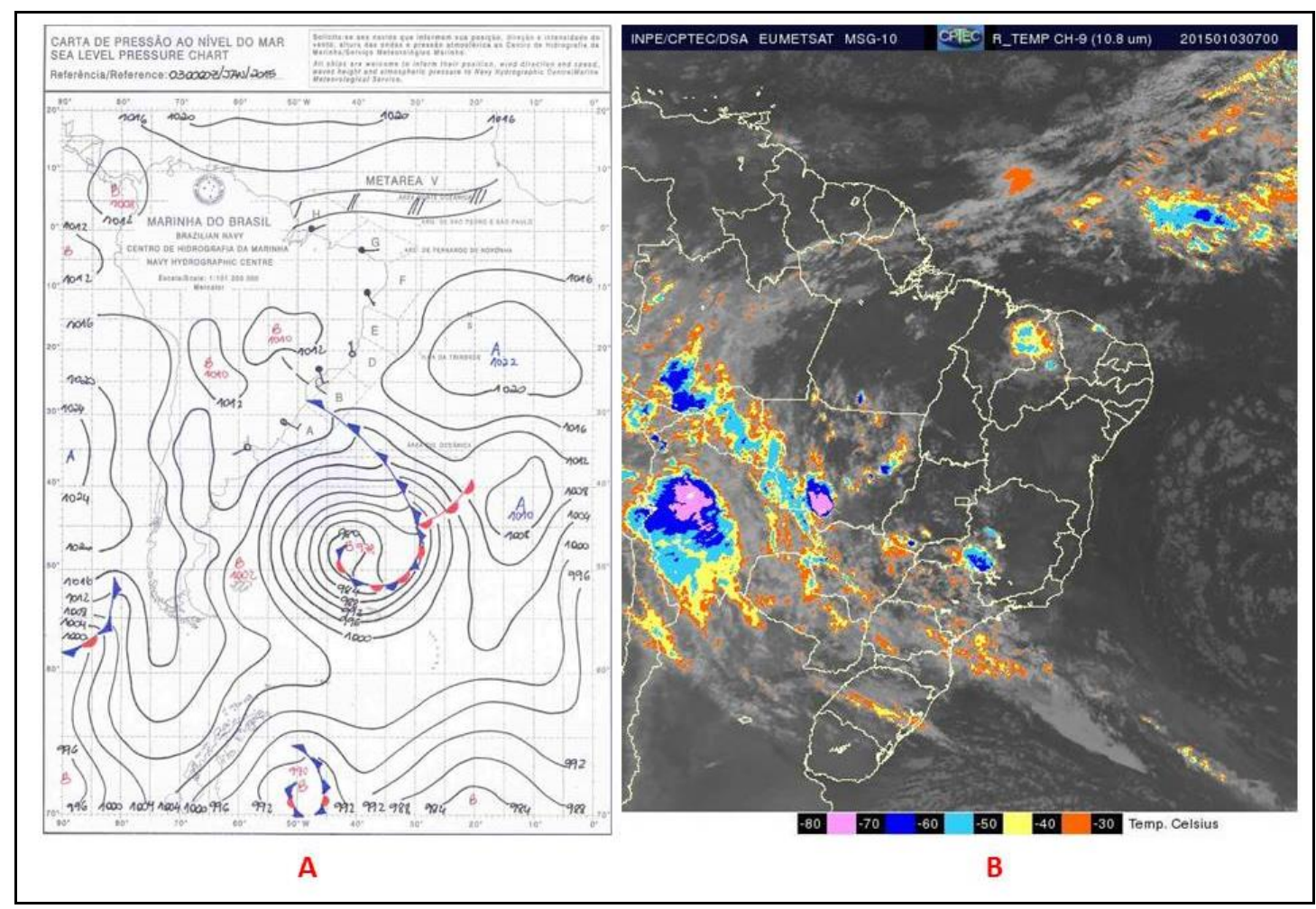

Fonte: Marinha do Brasil e CPTEC/INPE, 2015.

Com base na carta sinótica e na imagem de satélite acima podemos perceber a atuação do vcan associados com as OL. Os VCAN's são caracterizados como sistemas de pressão relativamente baixa no centro, com forma aproximada de um círculo girando no sentido horário, na sua periferia há formação de nuvens causadoras de chuva na sua periferia e no centro movimentos verticais de subsidência e ascendência na periferia. (FERREIRA e MELLO, 2005; FERREIRA, RAMÍREZ e GAN, 2009; FERREIRA, 2006). 
A chuva do dia 03 de janeiro de 2015 foi rápida e intensa, começou por volta das cinco da manhã e às nove horas parte do morro Santa Teresinha, localizao no bairro Vicente Pinzón em Fortaleza, havia sofrido com deslizamentos (Imagem 02), isso prejudicou a infraestrutura de várias casas, onde cinco casas tiveram de ser demolidas e 20 residências que correm risco de desabamento foram isoladas pela defesa civil.

\section{Imagem 02: Deslizamento do morro Santa Teresinha.}

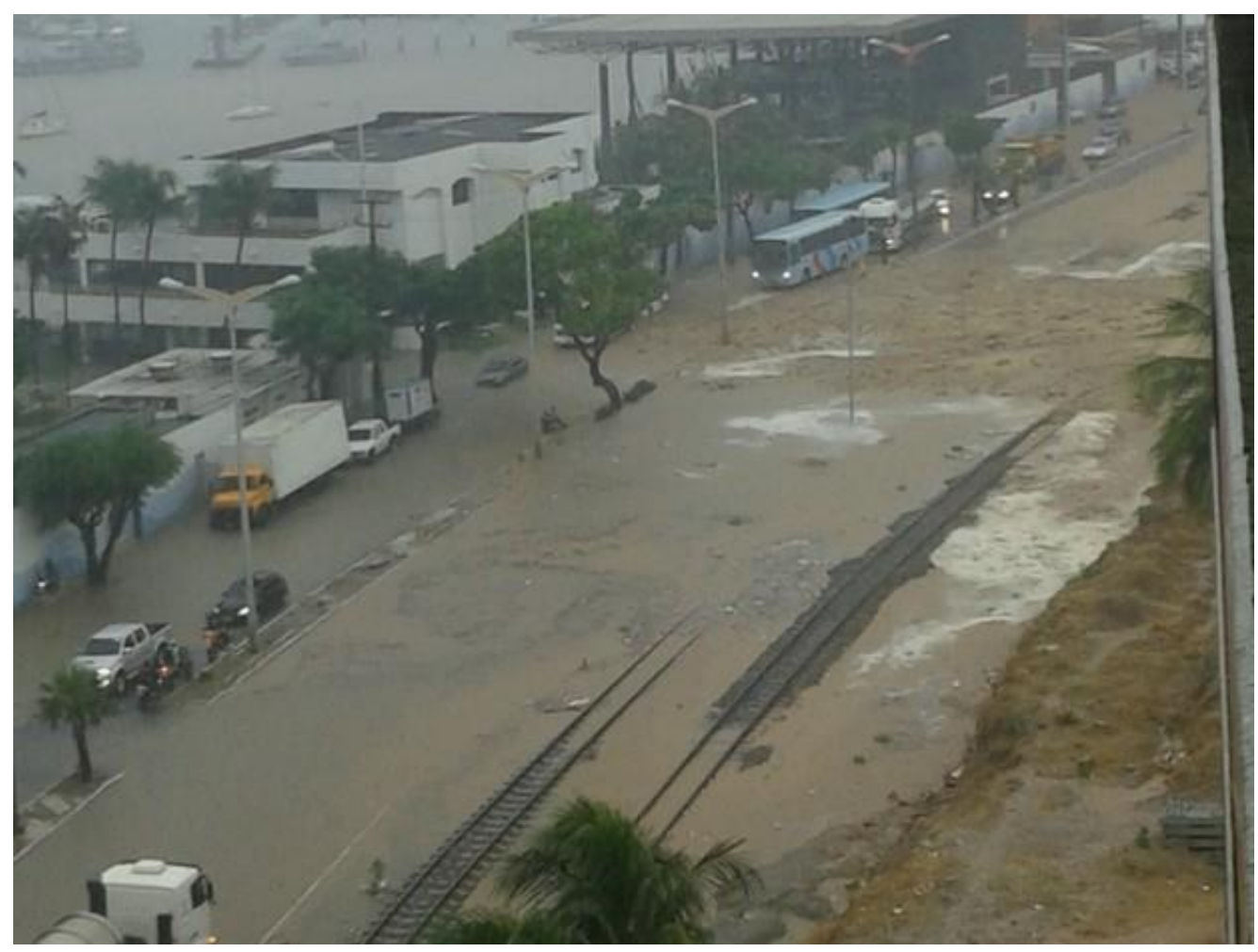

Fonte: O Globo, 2015.

Além disso, parte do teto de um shopping na cidade desabou, o Hospital Geral de Fortaleza (HGF) também sofreu com infiltrações e alagamentos, as ruas Botelho Ramos (Papicu) e José Frota (Cidade dos Funcionários); e as avenidas Heráclito Graça e Abolição ficaram alagadas e parte de um estacionamento de um prédio cedeu (Imagem 03). 


\section{Imagem 03: A- Avenida Abolição; B- Registro de raio na cidade; C- Rua alagada, D-} Teto de shopping.

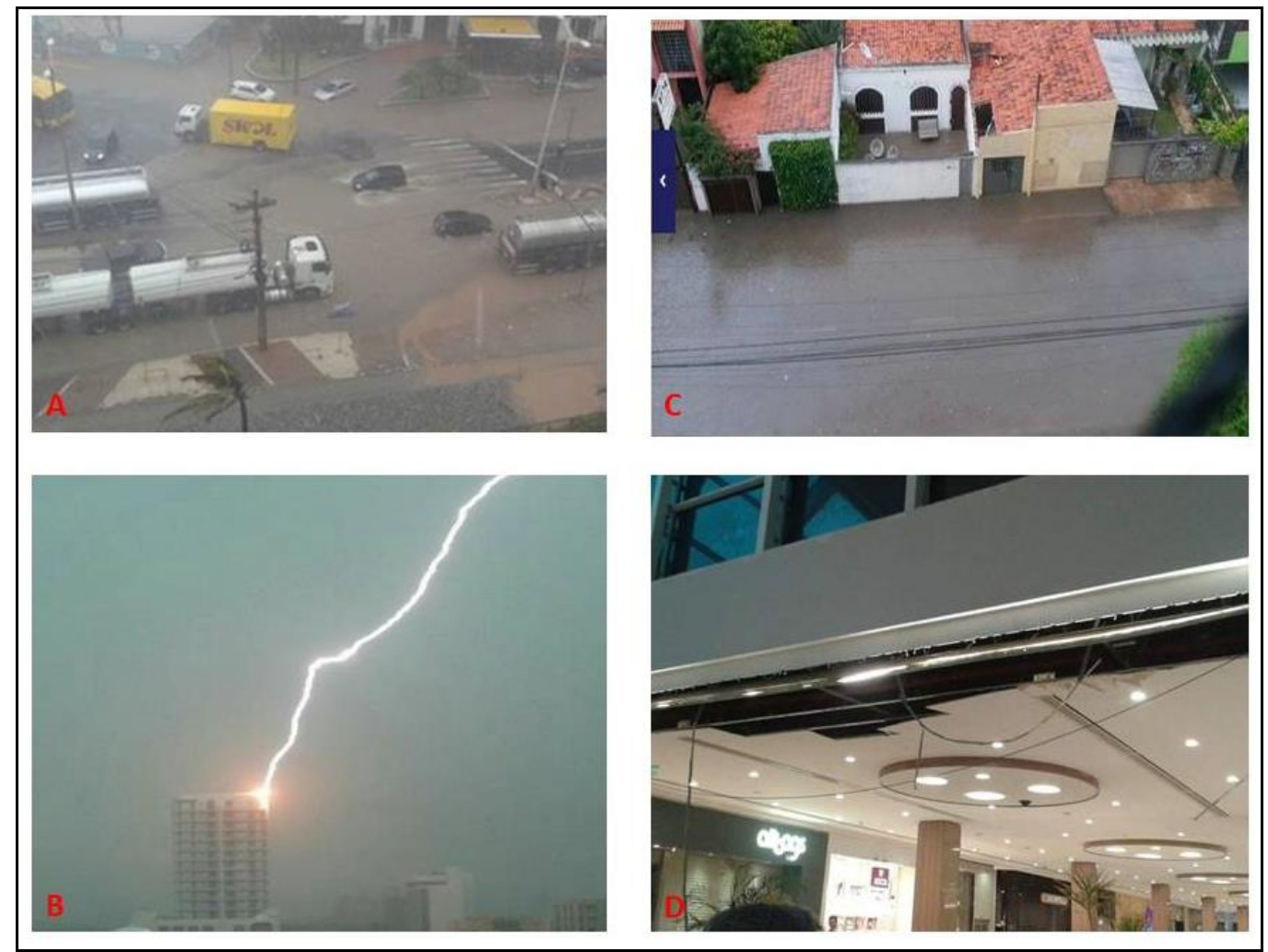

Fonte: A, D- O Globo; C, B- Tribuna do Ceará, 2015.

A COELCE (Companhia de Energia Elétrica do Ceará) junto com o Instituto Nacional de Pesquisas Espaciais (ELAT/INPE) registraram 97 descargas atmosféricas - raios, em quatro horas na cidade de Fortaleza (O POVO, 2015). Os raios são comuns em chuvas ocasionadas por VCAN devido à alta instabilidade atmosférica.

Apesar da chuva forte não houve inundações, pois, os rios que abastecem a cidade estão com nível baixo devido à sequência de anos secos. Os principais impactos foram na parte "nobre da cidade" onde o maior registro de chuvas se deu no posto pluviométrico localizado no bairro Edson Queiroz.

A Defesa Civil juntamente com a FUNCEME tem participado de um projeto que visa minimizar os impactos desses eventos pluviométricos intensos, é um sistema de alerta para a cidade de Fortaleza, que tem como objetivo avisar os moradores das áreas de risco sobre os perigos de um evento desses e da necessidade deles saírem do local para sua segurança, porém, ele só foi lançado no dia 29 de janeiro, após o evento de chuva em questão. 


\section{CONSIDERAÇÕES FINAIS}

A cidade de Fortaleza sofre muito com os impactos gerados em detrimentos dos eventos de chuva extrema, isso ocorre devido às mudanças feitas pela sociedade para adaptar o quadro natural do sítio urbano conforme as suas necessidades, ou melhor, conforme as necessidades impostas pelo capital. Essas alterações, como: impermeabilização do solo, construção de prédios altos, desmatamento; geram uma alteração no balanço de energia que acabam alterando o clima local, produzindo um Clima Urbano.

Como a maioria das cidades brasileiras não tem um planejamento adequado, somamse fatores que potencializam os efeitos/impactos de chuvas mais intensas, que talvez, em outras condições não seriam tão danosas. Porém, a falta de planejamento, aliada a ocupações inadequadas (em áreas de risco) e as mudanças no clima local se unem propiciando a ocorrência desses eventos que acabam acontecendo com maior frequência.

Neste trabalho, dentro do período analisado, houve uma média de 3 eventos de chuva extrema por ano. Esses eventos ocorrem mais frequentemente e com maior intensidade em anos chuvosos, porém, mesmo em anos secos ou tendente a secos eles aparecem, somente nos anos de 2013 e 2014 não foi registrado nenhum evento desse tipo.

A distribuição desses eventos se concentram no primeiro semestre do ano, que como dito anteriormente, é o período chuvoso para a região. Os messes em que mais esses eventos ocorrem são março, abril e maio, com pico máximo em abril, isso se deve a atuação da ZCIT que neste período do ano encontra-se em sua posição mais ao sul, favorecendo as chuvas na região. Contudo, o mês de janeiro se apresenta como um mês onde há ocorrência de eventos de chuva extrema é bastante significativa, isso ocorre devido a atuação dos VCAN's, que são sistemas típicos da nossa pré-estação chuvosa, no ano de 2011 eles foram muito atuantes, e no dia 03 de janeiro de 2015, evento que destacamos no trabalho, houve a atuação de um VCAN associado as OL.

No evento do dia 03 de Janeiro de 2015, a região que mais sofreu com os impactos da chuva foi à região norte e leste de Fortaleza, onde se encontram os bairros de classe média alta (Meireles, Papicu, Edson Queiroz) e também alguns bairros mais pobres como Vicente Pinzón onde ocorreu o deslizamento do Morro Santa Teresinha.

O presente trabalho serve como um alerta, tanto para as autoridades e gestores locais, como para população da necessidade de se planejar melhor a cidade e de tentar minimizar os impactos desses eventos e, também, buscar preservar mais o ambiente e implantar mais áreas 
verdes na cidade. $O$ trabalho contribui ainda com a comunidade acadêmica de estudos posteriores sobre os eventos de chuva extrema na cidade de Fortaleza.

\section{REFERÊNCIAS}

ACCIOLY, Vera Mamede. Mobilidade e expansão urbana na Região Metropolitana de Fortaleza: da concentração a dispersão urbana. In: DANTAS, E. W. C; COSTA, M. C. L. (Org.). Vulnerabilidade Socioambiental na Região Metropolitana de Fortaleza. Fortaleza: UFC, 2009. p. $99-138$.

CARLOS, Ana Fani. Espaço e Indústria. 7 Ed. São Paulo: Contexto, 1997. O espaço urbano. Novas abordagens sobre a cidade. São Paulo: Contexto, 2007.

COSTA, Maria Clélia Lustosa. Arranjo familiar e vulnerabilidade na Região Metropolitana de Fortaleza. In: DANTAS, E. W. C; COSTA, M. C. L. (Org.). Vulnerabilidade Socioambiental na Região Metropolitana de Fortaleza. Fortaleza: UFC, 2009. p. 139-164.

DANTAS, Eustógio Wanderley Correia. O Centro de Fortaleza na contemporaneidade. In: DANTAS, E.W.C; COSTA, M.C.L; SILVA, J.B. da; (Otg). De cidade a Metrópole (Trans) formações urbanas em Fortaleza. Fortaleza: UFC, 2009, p. 187- 228.

FERREIRA, Antonio Geraldo; MELLO, Namir Giovanni da Silva. Principais Sistemas Atmosféricos Atuantes Sobre a Região Nordeste do Brasil e a Influência dos Oceanos Pacífico e Atlântico no Clima da Região. Revista Brasileira de Climatologia, Curitiba, v. 1, n. 1, 2005.

FERREIRA, Arthur Gonçalves. Meteorologia prática. São Paulo. Oficina de Textos, 2006. FERREIRA, Nelson J.; RAMÍREZ, Maria Valverde; GAN, Manoel Alonso. Vórtices Ciclônicos de Altos Níveis que Atuam na Vizinhança do Nordeste do Brasil. In.: CAVALCANTI, Iracema F. A.; et al (Orgs.). Tempo e Clima no Brasil. São Paulo. Oficina de Textos, 2009. p. 43-59.

FREIRE, Lusiana. Em Fortaleza, chove 82 milímetros em 4 horas. O POVO, Fortaleza, 03 de jan. 2015.2 Disponível em: http://www20.opovo.com.br/app/fortaleza/2015/01/03/noticiafortaleza,3371327/temporalatinge-fortaleza-e-cidades-do-interior.shtml. Acesso em: 14 de março de 2015. 
GONÇALVES, Neyde Maria Santos. Impactos pluviais e desorganização do espaço urbano de Salvador. In.: MONTEIRO; Carlos Augusto de Figueiredo; MENDONÇA, Francisco (Orgs). Clima Urbano. 2 Ed. São Paulo, Contexto, 2011. p. 69-92.

FIOCRUZ (Org's). Projeto Observatorium. Inventário de dados sobre eventos climáticos extremos. IV Oficina do Observatório de Clima e Saúde. Rio de Janeiro, 2011.

MACHADO, Tiago Almeida. A percepção de eventos extremos de frio - Caso de estudo: Freguesia de Santo Tirso. 2013. 176 f. Dissertação. Universidade de Porto, Porto. 2013.

MARENGO, Jose A. Impactos de extremos relacionados com o tempo e o clima Impactos sociais e econômicos. In.: Boletim do Grupo de Pesquisa em Mudanças Climáticas. Número 8 - Maio de 2009 - Edição Especial.

MENDONÇA, Francisco de Assis. Geografia e meio ambiente. 8 Ed. São Paulo, Contexto, 2010.

MONTEIRO; Carlos Augusto de Figueiredo; MENDONÇA, Francisco (Orgs). Clima Urbano. 2 Ed. São Paulo, Contexto, 2011.

PEQUENO, Renato. Estrutura intraurbana socioocupacinal \& condição desigual de moradia na Região Metropolitana de Fortaleza. In: DANTAS, E. W. C; COSTA, M. C. L. (Org.). Vulnerabilidade Socioambiental na Região Metropolitana de Fortaleza. Fortaleza: UFC, 2009. p. 55-98.

SANTOS, Milton. Técnica, espaço, tempo: globalização e meio técnico-científico informacional. São Paulo: Hucitec, 2008.

TOMINAGA, Lídia Keiko; SANTORO, Jair; AMARAL, Rosangela do (Orgs.). Desastres naturais: conhecer para prevenir. São Paulo: Instituto Geológico, 2009.

ZANELLA, Maria Elisa; SALES, Marta Celina Linhares; ABREU, Nair Júlia Andrade. Análise das precipitações diárias intensas e impactos gerados em Fortaleza, CE. GEOUSP, São Paulo, n. 25, 2009. p. 53 - 68.

ZANELLA, Maria Elisa. Vulnerabilidade Socioambiental de Fortaleza. In: DANTAS, E. W. C; COSTA, M. C. L. (Org.). Vulnerabilidade Socioambiental na Região Metropolitana de Fortaleza. Fortaleza: UFC, 2009. p. 191-216.

Vulnerabilidade socioambiental do baixo curso da bacia hidrográfica do Rio Cocó, fortaleza-ce. Sociedade \& Natureza, Uberlândia, v. 25, n. 2, p.317-332, ago. 2013. 